\section{FRI0560 EFFICACY AND SAFETY OF ANAKINRA IN SYSTEMIC JUVENILE IDIOPATHIC ARTHRITIS - DATA OF THE BIKER REGISTRY}

Ariane Klein, Veronika Ntam Atemnkeng, Frank Dressler, Ivan Foeldvari, Rolf Michael Küster, Toni Hospach, Gerd Ganser, Kirsten Minden, Dirk Foell,

Frank Weller-Heinemann, Jasmin Kuemmerle-Deschner, Boris Huegle, Christoph Rietschel, Eggert Lilienthal, Gerd Horneff, BIKER-Registry. BIKERRegistry, Sankt Augustin, Germany

Background: Anakinra (ANA) is recommended for treatment of systemic juvenile idiopathic arthritis (sJIA) and has recently received EMA approval. Objectives: To describe safety and effectiveness of ANA in clinical practice in SJIA patients documented in the German Biologics registry (BiKeR).

Methods: Demographic and clinical parameters of the patients were recorded at BiKeR enrollment, ANA effectiveness was evaluated by halfyearly evaluation of disease activity using JADAS-10. Safety assessments were based on MedDRA-coded adverse events (AE) reports.

Results: Until December 12018,50 sJIA patients treated with ANA were registered, representing 113.4 patient-years (PY) of observation, with 10 patients $(20 \%)$ receiving ANA for at least 4 years. The cohort treated with ANA had experienced a prior disease duration of 3.5+/-3.8 years (mean+/-SD).

Most sJIA patients treated with ANA received pretreatment: 35 patients $(70 \%)$ were pretreated with at least one other biologic, mostly etanercept $(n=28)$, followed by tocilizumab (6) and canakinumab (1). Further pretreatments included methotrexate (MTX, $n=35)$, ciclosporine $A(n=13)$, azathioprine $(n=8)$ and other DMARDs at lower frequency. 39 patients had received corticosteroids. Concomitant treatment consisted of NSAIDs $(n=20)$, systemic steroids $(n=35)$, MTX $(n=29)$ and other DMARDs $(n=8)$.

At month 3, JADAS minimal disease activity (MDA)/JADAS remission and inactive disease according to Wallace [1] were observed in $42 \% / 37 \%$ and $47 \%$, respectively. After one year of treatment, the rates were $62 \% / 45 \%$ and $56 \%$, respectively (Figure 1 ).

Conclusion: The current analysis adds to the established safety profile of Anakinra and demonstrates that in ANA treated patients with SJIA the rate of SAEs was comparable and consistent with the overall $A E$ profile of ANA in pediatric patients. Hospitalisation was the usual reason for classification as serious AE. No new safety signals specific to the paediatric population were identified in this large cohort of JIA patients.

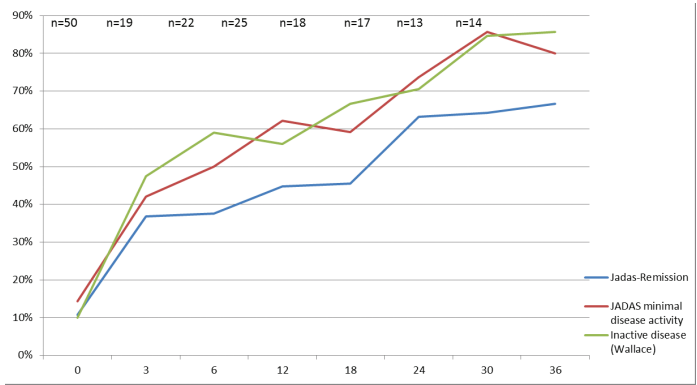

Figure 1: Efficacy parameter over time (months) in JIA patients treated with Anakinra

Disclosure of Interests: Ariane Klein: None declared, Veronika Ntam Atemnkeng: None declared, Frank Dressler Paid instructor for: Abbvie, Pfizer, Novartis, Ivan Foeldvari Consultant for: Chugai, Novartis, Rolf Michael Küster: None declared, Toni Hospach Speakers bureau: Chugai, Roche, Novartis, Gerd Ganser: None declared, Kirsten Minden Consultant for: AbbVie, Dirk Foell Grant/research support from: not specified, Consultant for: not specified, Speakers bureau: not specified, Frank Weller-Heinemann: None declared, Jasmin Kuemmerle-Deschner Grant/research support from: Jasmin Kuemmerle-Deschner is an employee of University of Tuebingen, Germany, and received consultants/speakers fees from Novartis and $\mathrm{SOBI}$ pharmaceuticals and grant support from SOBI and Novartis., Consultant for: Jasmin Kuemmerle-Deschner is an employee of University of Tuebingen, Germany, and received consultants/speakers fees from Novartis and SOBI pharmaceuticals and grant support from SOBI and Novartis., Speakers bureau: Jasmin Kuemmerle-Deschner is an employee of University of Tuebingen, Germany, and received consultants/ speakers fees from Novartis and SOBI pharmaceuticals and grant support from SOBI and Novartis., Boris Huegle: None declared, Christoph Rietschel: None declared, Eggert Lilienthal: None declared, Gerd Horneff: None declared

DOI: 10.1136/annrheumdis-2019-eular.2608

\section{FRI0561}

COMPARISON OF INITIAL PRESENTATIONS BETWEEN JUVENILE IDIOPATHIC ARTHRITIS CHILDREN WITH SYSTEMIC ONSET WITH NON-BIOLOGIC MONOCYCLIC AND PERSISTENT COURSES

Mikhail Kostik, Maria Rumyantseva, Eugenia Isupova, Irina Chikova,

Margarita Dubko, Vera Masalova, Ludmila Snegireva, Tatiana Kornishina,

Tatiana Likhacheva, Ekaterina Gaidar, Andrey Santimov, Olga Kalashnikova.

Saint-Petersburg State Pediatric Medical University, Saint-Petersburg, Russian

Federation

Background: Juvenile idiopathic arthritis with systemic onset (soJIA) may have monocycling, polycycling or relapsed course [1]. There were not known soJIA course predictors.

Objectives: The aim of our study was to evaluate initial clinical or laboratory features of the patients with soJIA who had monocyclic course without biologics.

Methods: In the present study were included data about 130 soJIA patients. After selection we identified a subgroup of the SoJIA patients $(n=22)$ who successfully achieved remission without any biologic medication and were stable in the remission off-medication at least two years. The second group consisted of the patients with chronic persistent course $(n=83)$. The remained 25 patients were excluded due to missing data or who did not meet the selection criteria. We evaluated routine clinical (fever, rash, hepatosplenomegaly, serositis, lymphadenopathy, MAS, joint involvement) and laboratorial (WBC, PLT, Hb, ferritin, ALS, AST, LDH, GGTP, ALP, albumin, Na, triglycerids, ESR, CRP, prothrombin, fibrinogen) soJIA features in the onset of the disease.

Results: Patient with monocycling course have no any differences except the ferritin level: $275(133 ; 698) \mathrm{ng} / \mathrm{ml}$ vs $950(150 ; 3240) \mathrm{ng} / \mathrm{ml}$, $(p=0.04)$, time to achievement remission $17.7(8.2 ; 38.0)$ months vs 60.2 $(36.0 ; 99.0)$ months $(p=0.00002)$ and rare elbow involvement $4.6 \%$ vs $30.9 \%(p=0.01)$. The parameters, associated with possible monocycling course are in the table.

Table. The parameters, associated with possible monocyclic course in soJIA patients

\begin{tabular}{|c|c|c|c|c|c|}
\hline Parameter & AUC $(95 \% \mathrm{Cl})$ & $\mathrm{Se}$ & Sp & OR $(95 \% \mathrm{Cl})$ & $\mathrm{p}$ \\
\hline $\mathrm{CRP} \leq 3.1 \mathrm{mg} / \mathrm{dl}$ & $\begin{array}{l}0.59(0.48 \\
0.69)\end{array}$ & 0.53 & 077 & $\begin{array}{c}3.6(1.3 ; \\
10.3)\end{array}$ & 0.014 \\
\hline $\mathrm{ESR} \leq 53 \mathrm{~mm} / \mathrm{h}$ & $\begin{array}{c}0.62(0.51 \\
0.71)\end{array}$ & 0.9 & 0.43 & $\begin{array}{c}6.8(1.5 \\
31.3)\end{array}$ & 0.006 \\
\hline Ferritin $\leq 1340 \mathrm{ng} / \mathrm{ml}$ & $\begin{array}{l}0.69(0.58 \\
0.79)\end{array}$ & 1.0 & 0.46 & - & 0.003 \\
\hline Active joints $<8$ & $0.5(0.4 ; 0.6)$ & 0.82 & 0.39 & $\begin{array}{c}4.6(1.3 \\
16.8)\end{array}$ & 0.013 \\
\hline Onset age $<7$ years & $\begin{array}{l}0.57(0.47 \\
0.66)\end{array}$ & 0.86 & 0.4 & $\begin{array}{c}4.2(1.5 \\
15.3)\end{array}$ & 0.022 \\
\hline $\begin{array}{l}\text { No elbow involvement, } n \\
(\%)\end{array}$ & - & 0.96 & 0.31 & $\begin{array}{c}9.4(1.2 \\
73.6)\end{array}$ & 0.012 \\
\hline
\end{tabular}

Conclusion: Patients with soJIA initially have quit similar clinical presentations independently the further clinical course. The prediction of possible course of soJIA is a difficult problem. Patients with soJIA with monocycling course were younger and had less impressive laboratory activity. Further investigations required.

\section{REFERENCE:}

[1] Cimaz R. Systemic-onset juvenile idiopathic arthritis. Autoimmun Rev. 2016;15(9):931-4.

Disclosure of Interests: None declared DOI: 10.1136/annrheumdis-2019-eular.7991

\section{FRI0562 CONCENTRATION OF SURVIVIN IN CHILDREN WITH JUVENILE IDIOPATHIC ARTHRITIS(JIA) - DIAGNOSTIC AND PROGNOSTIC VALUE}

Joanna Lipinska ${ }^{1}$, Joanna Swidrowska-Jaros ${ }^{1}$, Krystyna Wyka $^{2}$,

Elzbieta Smolewska ${ }^{1} .{ }^{1}$ Medical University of Lodz, Department of Pediatric Cardiology and Rheumatology, Łódź, Poland; ${ }^{2}$ Medical University of Lodz, Department of Pediatrics, Oncology, Hematology and Diabetology, Lodz, Poland

Background: Survivin is an anti-apoptotic protein that has been suggested as a predictive marker of severe course of adult rheumatoid arthritis and could be used for preclinical recognition of rheumatoid process.

Objectives: The goal of the study was to evaluate the diagnostic and prognostic value of survivin in Juvenile Idiopathic Arthritis (JIA). 